\title{
Role of Layer by Layer Irrigation by Povidone Iodine during Closure of Potentially Contaminated Wounds in Reduction of Surgical Site Infection
} Abd Alla Abd Alhamid Sallam, Mostafa Mahmoud Salama, Hamada Mohamed Fahmy Alshaer*

Department of General Surgery, Faculty of Medicine, Al-Azhar University

* Corresponding author: Hamada Mohamed Alshaer, E-Mail: 7amadasha3er@gmail.com

\begin{abstract}
Background: surgical site infection (SSI) is the infections occurring up to 30 days after surgery that affect the incision, deep tissue at the operation site or involve the organs or body space. Infection at the surgical site remains the second most common adverse event occurring to hospitalized patients and a major source of morbidity following surgical procedures.

Aim of the Work: this study was done to assess the role of irrigation of partially contaminated wounds by povidone iodine in reduction of surgical site infection.

Patients and Methods: this descriptive prospective study was carried out on 100 patients of potentially contaminated wounds at El-Hussein University Hospital and others, Patients divided into two groups A\&B each group consisted of fifty patients, Group A: their wounds irrigated layer by layer with povidone iodine during closure, Group B: their wounds closed without irrigation with povidone iodine.

Results: total number of cases with SSI in our study is twenty cases $20 \%$ of the total count. In group A there was nine cases two of them showed pus formation. While, in group B there was eleven cases eight of them undergo pus formation.

Conclusion: from our study we concluded that The irrigation of the subcutaneous tissue during closure of potentially (clean) contaminated wounds layer by layer by povidone-iodine $10 \%$ solution did not significantly reduces the surgical site infection percentage but significantly reduced the formation of pus within the infected wound cavity and thus reducing the severity of surgical site infection.
\end{abstract}

Keywords: Surgical site infection (SSI), Potentially (clean) contaminated wound, Povidone-iodine (PVI), Irrigation.

\section{INTRODUCTION}

Surgical site infection (SSI) is the infections occurring up to 30 days after surgery that affect the incision, deep tissue at the operation site or involve the organs or body space $^{(\mathbf{1})}$. Despite considerable research on best practices and strides in refining surgical techniques, technological advances and environmental improvements in the operating room (OR), and the use of prophylactic preoperative antibiotics, infection at the surgical site remains the second most common adverse event occurring to hospitalized patients and a major source of morbidity following surgical procedures $(2,3)$. All surgical wounds are contaminated by bacteria, but only a minority actually demonstrates clinical infection. In most patients, infection does not develop because innate host defenses are quite efficient in the elimination of contaminants at the surgical site. The Centre for disease control and prevention (CDC) ${ }^{(1)}$ has established four wound classes based on the degree of contamination with pathogens; Clean, Clean-contaminated, Contaminated and Dirty-infected wounds. The evidence reveals that the risk of SSI increases if the surgical wound is contaminated with more than 105 microorganisms per gram of tissue. However, this threshold is reduced when foreign bodies, such as detritus, sutures, and drains, are present in the surgical wound ${ }^{(4)}$. Clean- contaminated wound is an operative wound in which the respiratory, alimentary, genital, or uninfected urinary tract is entered under controlled conditions, including controlled contamination by the contents of the relevant $\operatorname{tract}(\mathrm{s})$, is rated clean contaminated or Class II. Specifically, operations involving the biliary tract, appendix, vagina, and oropharynx are included in this category, provided there is neither evidence of infection nor major break in technique. SSI rates in this class of procedures ranges from $4 \%$ to $10 \%{ }^{(\mathbf{1})}$. Most SSIs are caused by gram-positive cocci, including Staphylococcus aureus (S aureus) and Staphylococcus epidermis, organisms colonizing a patient's skin. Meanwhile, there is an increased likelihood of infection caused by gramnegative bacilli after surgery on the GI tract; Enterococcus faecalis and Escherichia coli are common pathogens after clean contaminated surgery ${ }^{(\mathbf{5}, \mathbf{6})}$. Intraoperative wound irrigation is the flow of a solution across the surface of an open wound to achieve wound hydration and it is widely practiced to help prevent $\operatorname{SSI}{ }^{(7,8)}$. It is intended to act as a physical cleaner by removing cellular debris, surface bacteria and body fluids, to have a diluting effect on possible contamination, and to function as a local antibacterial agent when an antiseptic or antibiotic agent is used. Up to $97 \%$ of surgeons state that they use intraoperative irrigation ${ }^{(7)}$. Evidence shows that the irrigation of the incisional wound with an aqueous povidone iodine (PVP-I) solution 
is beneficial with a significant decrease of the risk of SSI when compared to irrigation with a saline solution. There was no evidence for a doseresponse effect with regard to the concentration of the PVP-I solution used ${ }^{(9)}$. The microbicidal activity of iodine appears to involve the inhibition of vital bacterial cellular mechanisms and structures, and oxidizes nucleotides fatty/amino acids in bacterial cell membranes, in addition to cytosolic enzymes involved in the respiratory chain, causing them to become denatured and deactivated ${ }^{(10)}$.

\section{AIM OF THE WORK}

The purpose of this study is to evaluate the role and efficacy of irrigating the potentially contaminated wounds by povidone iodine in reduction of surgical site infection.

\section{PATIENTS AND METHODS}

This descriptive prospective study was carried out on 100 patients of potentially contaminated wounds at El-Hussein University Hospital and others. Patient's selection for this study based on clinical diagnosis, ultrasonographic findings and laboratory findings suggesting the type of wound of the research. The study was approved by the Ethics Board of Al-Azhar University. The patients included in the group of the study underwent surgery under the category of potentially (clean) contaminated wound in which the alimentary tract was entered under controlled conditions without unusual contamination. Specifically, surgical procedures involving the biliary tract, appendix, and the intestine provided no evidence of infection is encountered and no major break in technique occurs. The following categories of patients were excluded from the studied groups:Patients with clean wounds, patients with contaminated or dirty wounds, patients with clean contaminated wounds irrigated with materials other than povidone iodine. Patients divided into two groups A\&B (each group consisted of fifty patients): Group A: all patients in this group their wounds irrigated layer by layer with povidone iodine during closure. Group B: all patients in this group their wounds closed without irrigation with povidone iodine. After approval of Local Ethics Committee, all patients included in the study or their relatives were informed well about the procedure and had an informed written consent before carrying the procedure, All the patients included in this study with potentially (clean) contaminated wounds were subjected to the following: Proper history taking: Patient demographics and clinical information including age, gender, comorbidities, medical history (hypertension, diabetes, cardiac), surgical history, personal history of smoking or alcohol intake. Proper physical examination: Proper physical examination to confirm the diagnosis of the condition. Preoperative preparation: Preoperative patient preparation included the correction of fluid and electrolytes imbalance. Routine preoperative laboratory investigations (CBC, coagulation profile, liver function tests and kidney function tests), abdominal ultrasound and CT were done if needed to confirm diagnosis. ECG and chest X-ray were done to assess the cardio-pulmonary condition. Written informed consent was obtained from all patients included in the study. Postoperative follow up: Postoperative analgesia was carried out during the first 24 hours and thereafter at the request of the patient. Patients were closely observed postoperatively for adequate pain control, urine output, care of drains, clinical examination and investigations were carried out regularly to follow up the patient general condition and to assess signs of surgical site infection. First wound inspection started after 24 hours postoperative and subsequently dressed and followed up for 30 days. All patients were discharged from the hospital by the second day except those with drains discharged after drain is removed. Later on, patients were followed up in the outpatient clinic up to one month later. Statistical methods: Qualitative data were described using number and percent. Quantitative data were described using mean and standard deviation for normally distributed data while abnormally distributed data were expressed using median, minimum and maximum. Comparison between different groups regarding categorical variables was tested using Chi-square test. When more than $20 \%$ of the cells have expected count less than 5, correction for chisquare was conducted using Fisher's Exact test or Monte Carlo correction.

\section{RESULTS}

The age of patients in group A ranged between 7-66 years old with a mean age of (26.86 \pm 15.47 ) years, While that of the group B ranged between 6-60 years old with a mean age of $(28.28$ 
\pm 14.53 ) years and the statistical analysis revealed that there was no statistical significant difference between patients of both groups as regarding age ( $\mathrm{p}$ $=1.145$ (NS). 26 cases out of cases of the group A $(26 / 50,52 \%)$ were males and 24 were females $(24 / 50,48 \%)$. While in group B 37 patients $(37 / 50$, $74 \%)$ were males and 13 of them $(13 / 50,26 \%)$ were females and the statistical analysis revealed that there was no statistical significant difference between patients of both groups as regarding sex $\mathrm{p}$ $=0.09(\mathrm{NS})$. Operative data: The type of operation in group "A" was about 40 appendectomies, 9 surgical cholecystectomies and 1 case of obstructed umbilical hernia with gangrenous loop of ileum within it. While in group " $\mathrm{B}$ " the type of operation was 40 appendectomies, 9 surgical cholecystectomies and one case of intestinal obstruction in the form of sigmoid volvulus. The operative time in group A ranged between 25-120 min with a mean value of (48.3) $\min \mathrm{p}=3.5752$. While that of group B ranged between 20-120 min with a mean value of (46.9) $\min (p=7.9304)$. And the statistical analysis revealed that there was no statistical significant difference between patients of both groups as regarding time of operation $(\mathrm{P}=0.001) \mathrm{NS}$.

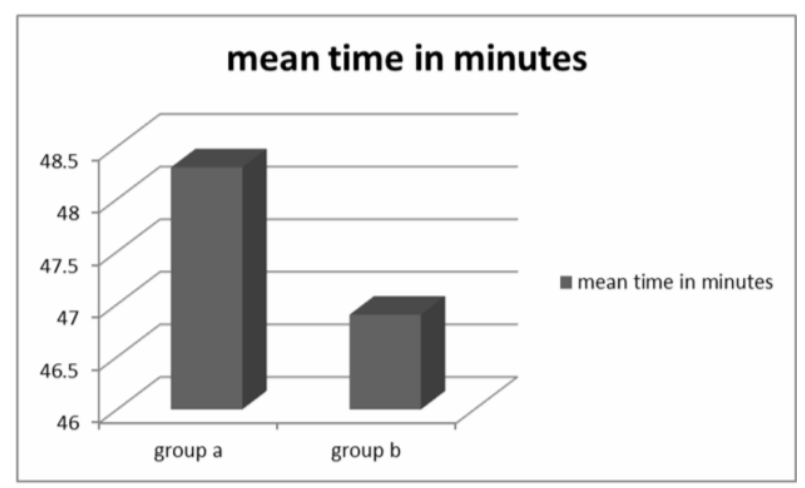

Fig. (1): time of operation in both groups.

23 cases in group A (46\%) experienced surgical drain insertion in the form of 13tube drain and 10 rubber drains, 5 of them developed SSI and the remaining cases of this group passed without insertion of drains, while in group B 26 cases (52\%) experienced surgical drain insertion 13 of both types, 7 of them developed SSI. The statistical analysis revealed that there was no statistical significant difference between patients of both groups as regarding SSI with inserted drains.

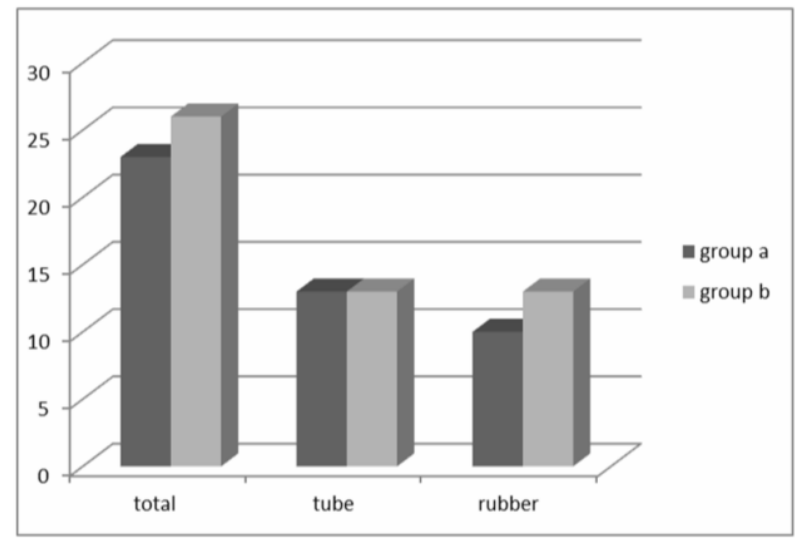

Fig. (2): surgical drains and type of them.

Intra-operative complications: 16 cases in group A (32\%) experienced intra-operative complications in the form of suppurative inflammation and perforation of the appendix with spillage of abundant pus. Reaction intra-peritoneum in 10 cases (20\%), bleeding at the bed after cholecystectomy in one case $(2 \%)$, bleeding from slipped ligature of appendicular artery in one case (2\%), meckeles diverticulum was found and wedge resection is done in one case (2\%), right ovarian hemorrhagic cyst was found and marsupialization was done in one case (2\%). A gangrenous ileum was found after opening of obstructed umbilical hernia then resection anastomosis was done in one case (2\%), bile leakage after perforation of gall bladder in one case (2\%), and the remaining cases of this group passed without complications. While in group B, 19 cases (38\%) experienced intra-operative complications in the form of suppurative inflammation and perforation of the appendix with spillage of abundant pus and reaction intra-peritoneum in 16 cases (32\%), leakage after perforation of gall bladder in two cases $(4 \%)$ and sigmoid volvulus with resection anastomosis in laparotomy due to intestinal obstruction in one case (2\%).

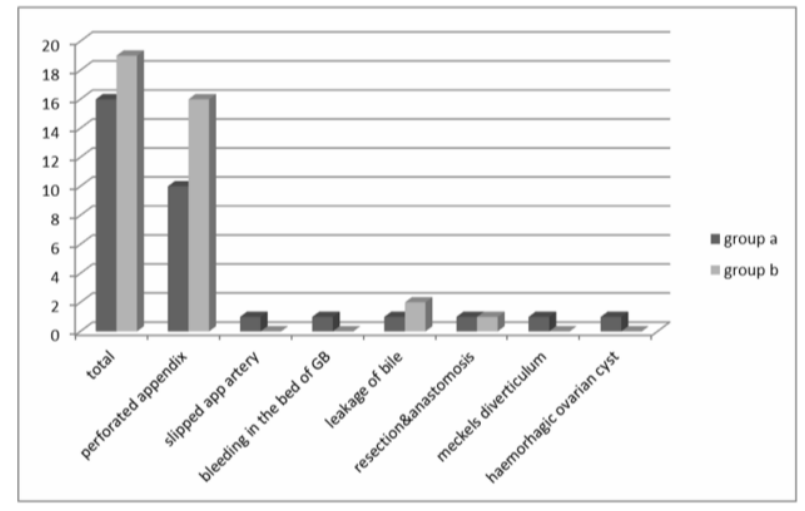

Fig. (3): Intraoperative complications in both groups. 
Table (1): Operative data of the studied groups

\begin{tabular}{|l|c|c|c|}
\hline \multicolumn{1}{|c|}{ Variable } & $\begin{array}{c}\text { Group } \\
\text { A }\end{array}$ & $\begin{array}{c}\text { Group } \\
\text { B }\end{array}$ & P \\
\hline Operative time & 72.5 & 70 & 0.001 \\
\hline $\begin{array}{l}\text { Insertion of } \\
\text { surgical drains }\end{array}$ & $\begin{array}{c}(23 / 50, \\
46 \%)\end{array}$ & $\begin{array}{c}(26 / 50, \\
52 \%)\end{array}$ & 0.841480581 \\
\hline $\begin{array}{l}\text { Intra-operative } \\
\text { complications }\end{array}$ & $\begin{array}{c}(16 / 50, \\
32 \%)\end{array}$ & $\begin{array}{c}(19 / 50, \\
38 \%)\end{array}$ & 0.002699796 \\
\hline
\end{tabular}

Follow-up Data: Post-operative hospital stay in patients of group A ranged between (24 hours - 6 days) with a mean value of $(1.72 \pm$ $1.1073)$ days. While in group B the hospital stay ranged between ( 24 hours -7 days) with a mean value of $(1.8 \pm 1.069)$ days and the statistical analysis revealed that there was no statistical significant differences between both groups ( $p$ $=0.995592541)$. Surgical site infection: Total number of cases with SSI in our study is twenty cases $20 \%$ of the total count. In group A there was nine cases two of them showed pus formation. While, in group B there was eleven cases eight of them undergo pus formation. Culture is taken from pus of all cases the most common microorganism was Staphylococcus aureus, Escherichia coli and anaerobes in nine cases which was susceptible to amoxicillinlclavulanate, ciprofloxacin, most cephalosporins and imipenem. Treated with iv ceftriaxone for one week, metronidazole orally and daily dressing. One case with pseudomonas aeruginosa which was resistant to amoxicillinlclavulanate and cefotaxime, treated with iv imipenem for 10 days with daily dressing. The surgical wound in both groups were examined up to 30 days post-operative and graded into five grades (0-4) in accordance with Southampton wound grading system, as shown in figure (4).

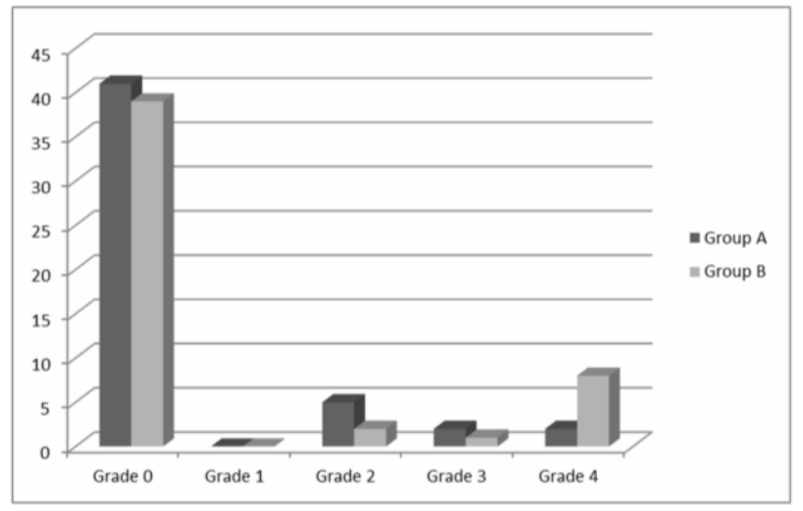

Figure (4): Southampton wound grading of clean contaminated wounds.
The frequency of patients in each Southampton grade was compared between two groups, as shown in table (2). A significantly higher number of patients $(\mathrm{p}<0.05)$ in control group B (eight patients) developed purulent discharge (pus) from wound site as compared to study group A (two patients).

Table (2): Comparison of wound infection between case and control group after irrigation of clean contaminated wound according to Southampton wound grading system.

\begin{tabular}{|l|c|c|c|c|}
\hline $\begin{array}{l}\text { Southampton Wound } \\
\text { grade }\end{array}$ & $\begin{array}{c}\text { Total } \\
\text { patients } \\
\mathbf{n = 1 0 0}\end{array}$ & $\begin{array}{c}\text { Group A } \\
\text { Povidone } \\
\text { irrigation } \\
\mathbf{n = 5 0}\end{array}$ & $\begin{array}{c}\text { Group B } \\
\text { No } \\
\text { irrigation } \\
\mathbf{n = 5 0}\end{array}$ & P-Value \\
\hline Grade 0: Normal healing & $\begin{array}{c}80 / 100 \\
(80 \%)\end{array}$ & $\begin{array}{c}41 / 50 \\
(82 \%)\end{array}$ & $\begin{array}{c}39 / 50 \\
(78 \%)\end{array}$ & 0.823063274 \\
\hline $\begin{array}{l}\text { Grade 1: Normal healing } \\
\text { + mild bruising }\end{array}$ & 0 & 0 & 0 & 0 \\
\hline $\begin{array}{l}\text { Grade 2: } \\
\text { Erythema/tenderness/heat }\end{array}$ & $\begin{array}{c}7 / 100 \\
(7 \%)\end{array}$ & $\begin{array}{c}5 / 50 \\
(10 \%)\end{array}$ & $2 / 50(4 \%)$ & 0.256839258 \\
\hline $\begin{array}{l}\text { Grade 3: Serous } \\
\text { discharge }\end{array}$ & $\begin{array}{c}3 / 100 \\
(3 \%)\end{array}$ & $2 / 50(4 \%)$ & $1 / 50(2 \%)$ & 0.563702862 \\
\hline $\begin{array}{l}\text { Grade 4: Purulent } \\
\text { discharge }\end{array}$ & $\begin{array}{c}10 / 100 \\
(10 \%)\end{array}$ & $2 / 50(4 \%)$ & $\begin{array}{c}8 / 50 \\
(16 \%)\end{array}$ & 0.057779571 \\
\hline
\end{tabular}

Southampton grade 2 and above was considered as surgical site infection. It was present in overall 20 patients (20\%), nine patients $(18 \%)$ from group A and 11 patients (22\%) from group B. The difference of surgical wound infection in the two groups was statistically insignificant $(\mathrm{p}=0.654720846)$.

\section{DISCUSSION}

Patients were divided into two groups, Group A, which consisted of 50 patients with clean contaminated wound that was irrigated by povidone iodine $10 \%$ during closure. Group B consisted of 50 patients with clean contaminated wounds, which was closed without irrigation. This study showed that although wound infection rate was not significantly reduced after preoperative irrigation of povidone-iodine $10 \%$; severity of infection was significantly less after subcutaneous irrigation by povidone-iodine $10 \%$. The overall frequency of wound infection in our study was $20 \%$, which is comparable to a wide range of clean contaminated wound infection of $4 \%$ to $10 \%$ from both local and international literature ${ }^{(11,12,13,14)}$. In a study from Lahore, Shah demonstrated superficial infection rate of $13.1 \%$ in open appendectomy patients, which represents clean contaminated wound ${ }^{(15)}$. Mughal and Soomro ${ }^{(11)}$ showed infection rate of $18 \%$ 
among pediatric population. However, there are studies with low infection rates. Ahmed et al. ${ }^{(\mathbf{1 8 )}}$ Reported wound infection rate of 5\% from Lahore, Chaudhry et al. ${ }^{(16)}$ showed infection rate of $6.4 \%$. One of the reasons for this varied presentation of wound infection after appendectomy is the inconsistent or non-standardized definitions of wound infection. In most of the local studies mentioned above the definition or criteria to label the wound as infected was not clearly mentioned ${ }^{(11,12,13,16)}$. Since these studies compared laparoscopic with open appendectomy, infection rates of the two groups can be compared but not with other studies ${ }^{(12,17)}$. In our study, we classified surgical wound according to Southampton wound grading system. This is the recommended classification of wound infection along with ASEPSIS score. CDC classification of surgical site infection has been used by various authors worldwide ${ }^{(\mathbf{1 7}, 19)}$. Southampton grade 2 and above was considered as surgical site infection. Purulent discharge from the surgical wound is the hallmark of ongoing infective process. This purulent discharge (pus) occurred due to the persistent production of inflammatory mediators, metabolic wastes and toxins by the microbial pathogens and along with virulence of the microorganism is a predictor of continued proliferation and growth of the microorganism ${ }^{(20)}$. Antiseptics are agents that destroy or inhibit the growth of microorganisms on living tissue hence limiting the formation of pus in the wound cavity ${ }^{(\mathbf{2 0}, \mathbf{2 1})}$. In our study, the irrigation of subcutaneous tissue with povidone-iodine $10 \%$ significantly reduced the formation of pus from the surgical wound; the infection rate was $4 \%$ in the treatment group and $16 \%$ in the control group (p < 0.001 ). The treatment group (povidone-iodine) did not experience any interference with wound healing or adverse reactions. Sindelar and Mason ${ }^{(22)}$ also showed that local irrigation of abdominal and urological wound with $10 \%$ povidone-iodine solution significantly lowered the formation of pus. The infection rate was $2.9 \%$ in the treatment group and $15.1 \%$ in the control group ( $\mathrm{p}<0.001)$. The treatment group (povidone-iodine10\%) did not experience any interference with wound healing or adverse reactions. Hiramatsu and colleagues ${ }^{(23)}$ in their study also demonstrated the beneficial effect of povidone-iodine application on subcutaneous tissue. They randomly allocated 59 patients into two groups. In the treatment group povidone-iodine gel was administered to the subcutaneous tissue and the skin was closed. While in the control group no intervention was done. Wound infection occurred in 18 patients, $5(16 \%)$ in treatment group and 13 $(46 \%)$ in the control group ( $p<0.05)$. Various other authors in their studies showed the effectiveness of povidone-iodine application for infection prophylaxis in abdominal, gynecological and ophthalmologic procedures ${ }^{(24,25)}$. The diagnosis of surgical site infection was based on Southampton wound assessment scale which was observerdependent and though observed by a single resident that had some degree of observer bias. No intervention was performed in the control group but irrigation with saline could be a possible solution for that.

\section{CONCLUSION}

From our study we concluded that The irrigation of the subcutaneous tissue during closure of potentially (clean) contaminated wounds layer by layer by povidone-iodine $10 \%$ solution did not significantly reduces the surgical site infection percentage but significantly reduced the formation of pus within the infected wound cavity and thus reducing the severity of surgical site infection.

\section{CONFLICTS OF INTEREST}

There are no conflicts of interest.

\section{REFERENCES}

1. Mangram AJ, Horan TC, Pearson ML, Silver LC, Jarvis WR (1999): Guideline for Prevention of Surgical Site Infection, Infection Control Hospital Epidemiology, 20(4):247-278.

2. Leape LL, Brennan TA, Laird N (1991): The nature of adverse events in hospitalized patients. Results of the Harvard Medical Practice Study II. N Engl. J. Med., 324(6):377-384.

3. Nathens AB, Cook CH, Machiedo G, Moore EE, Namias N, Nwariaku $F$ (2006): Defining the research agenda for surgical infection: consensus of experts using the Delphi approach. Surg. Infect (Larchmt ), 7(2):101-110.

4. Manring MM, Calhoun JH, Marculescu C (2009): Minimizing the Risk of Postoperative Infection. Current Orthopedic Practice, 20(4). 
5. Barie PS (2002): Surgical Site Infections: Epidemiology and Prevention. Surgical Infections, 3 (1):9-21.

6. Hidron AI, Edwards JR, Patel J (2008): Antimicrobial-Resistant Pathogens Associated with Healthcare Associated Infections. Annual Summary of Data Reported to the National Healthcare Safety Network at the Centers for Disease Control and Prevention, 2006-2007. Infection Control and Hospital Epidemiology, 29(11):996-1011.

7. Whiteside OJ, Tytherleigh MG, Thrush S, Farouk R, Galland RB (2005): Intraoperative peritoneal lavage, who does it and why? Ann R Coll Surg Engl., 87(4):255-8.

8. Pivot D, Tiv M, Luu M, Astruc K, Aho S, FournelI (2011): Survey of intraoperative povidone-iodine application to prevent surgical site infection in a French region. J. Hosp. Infection, 77(4):363-4.

9. World Health Organization (2016): WHO, Global Guidelines for the Prevention of Surgical Site Infection. www.who.int/ gpsc/ssi-prevention-guidelines/en/

10. Kanagalingam J, Feliciano R, Hah JH, Labib H, Le Lin TA (2015): Practical use of povidone-iodine antiseptic in the maintenance of oral health and in the prevention and treatment of common oropharyngeal infections, Int. J. Clin. Pract., $691247 \mathrm{e} 1256$.

11. Mughal SA, Soomro S (2007): Acute appendicitis in children. J. Surg. Pak., 12:123-5.

12. Perveen S, Sarwar G, Saeed N, Channa GA (2007): Laparoscopic versus open appendicectomy as an elective procedure. Med. Channel, 13:18-20.

13. Arshad M, Aziz LA, Qasim M, Talpur KA (2008): Early appendicectomy in appendicular mass: a Liaquat University hospital experience. J. Ayub Med. Coll. Abottabad, 20:70-2.

14. Kouwenhoven EA, Repelaer van Driel OJ, van Erp WF (2005): Fear for the intraabdominal abscess after laparoscopic appendectomy: not realistic. Surg. Endosc., 19:923-36.
15. Shah SA (2008): Laparoscopic appendicectomy versus conventional open appendicectomy: A study at Lahore General Hospital. Esculapio J. Services Inst. Med. Sci., 3:21-24.

16. Chaudhary IA, Samiullah MAA, Afridi Z, Bano A,(2005): Is it necessary to invaginate the stump after appendicectomy? Pak. J. Med. Sci., 21:35-8.

17. Horan TC, Gaynes RP, Martone WJ, Jarvis WR, Emori TG (1992): CDC definitions of nosocomial surgical site infections, a modification of CDC definitions of surgical wound infections. Infect. Control Hosp. Epidemiol., 13:606-8.

18. Ahmad N, Abid KJ, Khan AZ, Shah ST (2002): Acute Appendicitis-Incidence of Negative Appendicectomies. Ann King Edward Med. Coll., 8: 32-4.

19. Jan Y (2014): Comparison of postoperative wound infection in open versus laparoscopic appendectomy. Rawal Med. J., 39:55-7.

20. Selvaggi G, Monstrey S, Van Landuyt K, Hamdi M, Blondeel P (2003): the role of iodine in antisepsis and wound management: a reappraisal, Acta Chir. Belg. ,103:241-247.

21. Drousou A, Falabella A, Kirsner RS (2003): Antiseptics on wounds: an area of controversy. Wounds, 15:149-66.

22. Sindelar WF, Mason GR (1979): Irrigation of subcutaneous tissue with povidone-iodine solution for prevention of surgical wound infections. Surg. Gynecol. Obstet., 148:227-31.

23. Hiramatsu $K$, Nagino $M$, Kamiya $J$, Kondo S, Kanai M, Miyachi M (1998): A new method to prevent wound infection: a controlled clinical trial in patients with combined liver and bile duct resection. Langenbecks Arch. Surg., 383:437-41.

24. Koederitz NM, Neely DE, Plager DA, Boehmer B, Ofner S, Sprunger DT (2008): Postoperative povidone-iodine prophylaxis in strabismus surg. J., 12:396-400.

25. Eason E, Wells G, Garber G, Hemmings R, Luskey G, Gillett P, (2004): Antisepsis for abdominal hysterectomy: a randomised controlled trial of povidone-iodine gel. BJOG., 111:695-9. 